\title{
New record of Dotilla intermedia (Brachyura: Ocypodidae) from Thailand
}

\author{
CHRISTOPHER J. ALLEN ${ }^{1,2}$, PAUL F. CLARK ${ }^{2}$, GORDON L.J. PATERSON ${ }^{2}$, LAWRENCE E. HAWKINS ${ }^{1}$ \\ AND CHITTIMA ARYUTHAKA ${ }^{3}$ \\ ${ }^{1}$ School of Ocean and Earth Science, University of Southampton, National Oceanography Centre, Southampton, European Way, \\ Southampton, Hants SO14 3ZN, UK, ${ }^{2}$ Department of Zoology, The Natural History Museum, Cromwell Road, London SW7 5BD, \\ UK, ${ }^{3}$ Department of Marine Science, Kasetsart University, Band Khen, Bangkok 10900, Thailand
}

\begin{abstract}
The identity of a dotillid intertidal crab from exposed sandy beaches within the Laem Son National Park along the Andaman Coast in Thailand was investigated. The species was identified as Dotilla intermedia De Man, 1888, which represents the first record of this species from Thailand. A description of the species is provided and a lectotype is designated from the type series.
\end{abstract}

Keywords: Dotilla intermedia, new record, Andaman Sea, Thailand, lectotype

Submitted 23 September 2010; accepted 19 December 2010

\section{INTRロDUCTION}

Crabs assigned to Dotilla are distinguished by their abdominal morphology, where the fourth somite overlaps the fifth and possesses a band of setae along its distal margin (Kemp, 1919). They can be found on tropical shores and mudflats from East Africa and the Red Sea eastwards to Japan (Alcock, 1900). Two species of Dotilla have been previously recorded from Thailand. Dotilla myctiroides (H. MilneEdwards, 1852) has a relatively wide distribution within Thailand, whilst Dotilla wichmanni De Man, 1892 has only been reported from the east coast of Thailand.

Exposed oceanic sandy beaches are one of the major habitat types within the Laem Son National Park in Ranong Province, Thailand. Dotilla crabs represent the numerically dominant intertidal fauna on these beaches, which occur in immense numbers with records of around 20 million crabs present along a $5 \mathrm{~km}$ stretch of beach (G. Paterson, personal observation). The carapace sculpting of Dotilla can be used to easily identify between the different species of the genus in the field (Kemp, 1919; Vogel, 1983). The estuarine and sheltered mangrove areas of the Laem Son National Park were inhabited by D. myctiroides. However, the species of Dotilla present on the exposed beaches was not either D. myctiroides or D. wichmanni, with the carapace sculpture suggesting that the species was $D$. intermedia De Man 1888. The aim of this study was to confirm the identification of $D$. intermedia from the exposed sandy beaches in the Laem Son National Park, Thailand.

\section{MATERIALS ANDMETHDDS}

Twenty-four specimens of the Dotilla intermedia were sampled for identification from two exposed oceanic sandy

Corresponding author:

C.J. Allen

Email: chris.allen@noc.ac.uk beaches of the Laem Son National Park in Ranong Province, Thailand, Prapas beach $\left(9^{\circ} 21^{\prime} 57^{\prime \prime} \mathrm{N} 98^{\circ} 23^{\prime} 41^{\prime \prime} \mathrm{E}\right)$ and Bang Ben $\left(9^{\circ} 36^{\prime} 11^{\prime \prime} \mathrm{N} 98^{\circ} 27^{\prime} 56^{\prime \prime} \mathrm{E}\right)$, between 2005 and 2008 . The specimens were collected by hand at low tide by excavating burrows and capturing the resident crabs. Specimens were preserved in $100 \%$ ethanol. The key to Dotilla by Kemp (1919) was used as a first reference point for identification. The first male pleopods were removed and mounted on

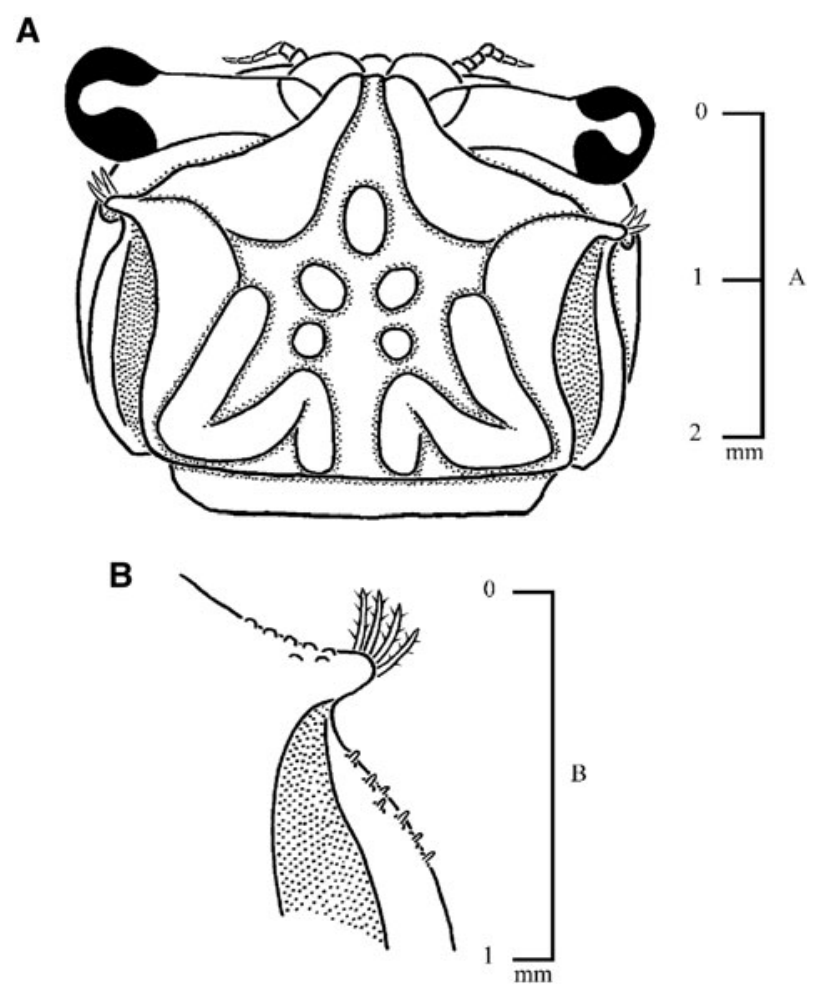

Fig. 1. Dotilla intermedia from the Laem Son National Park. (A) Carapace, dorsal view; (B) right antero-lateral margin, dorsal view. 

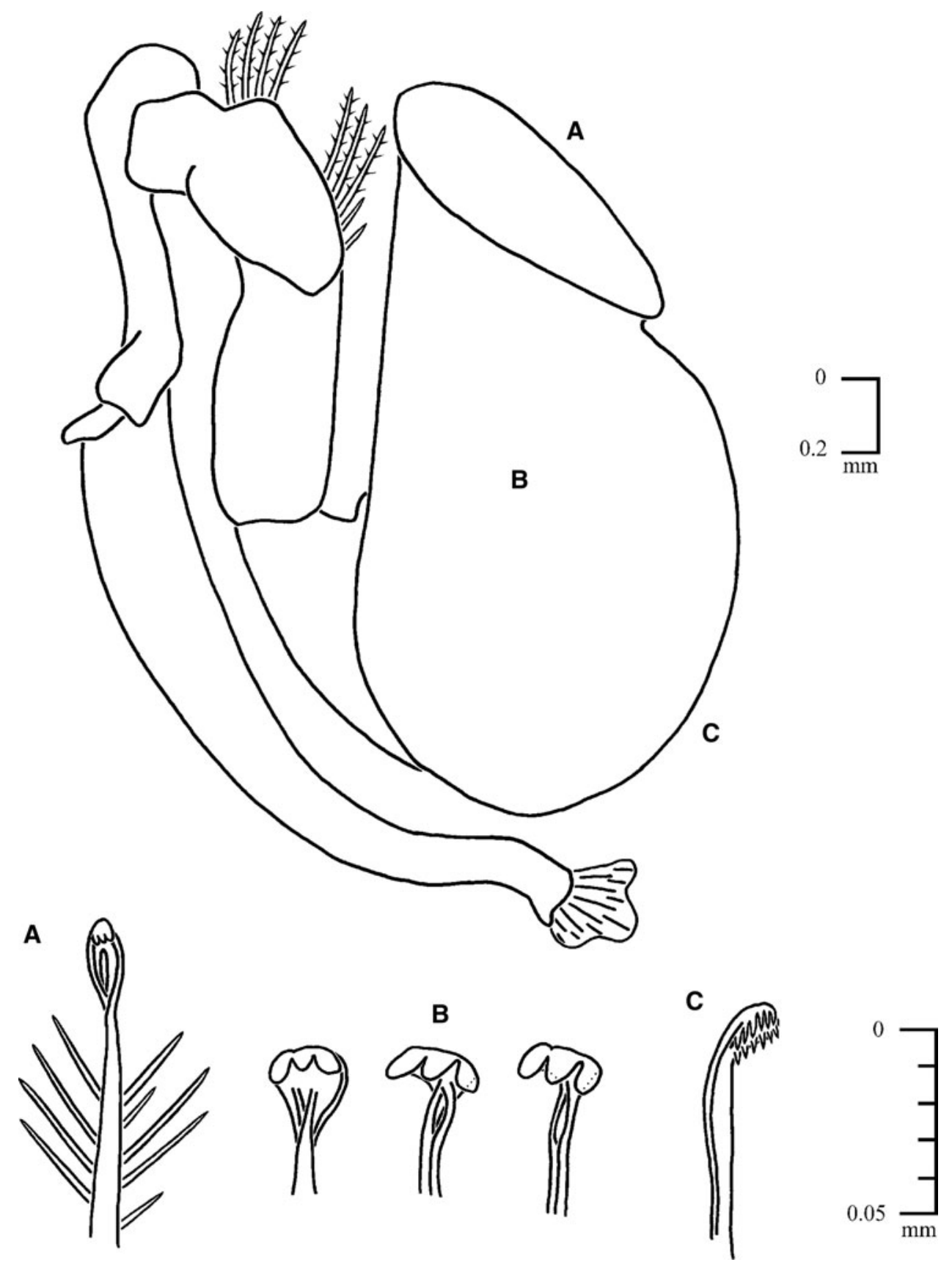

Fig. 2. Dotilla intermedia from the Laem Son National Park. Second maxilliped and spoon-tipped setae found on three regions of the maxilliped. (A) Along the proximal edge of the carpus; (B) on the inner surface of the merus; (C) along the proximal edge of the merus.

slides in polyvinyl lactophenol. Drawings of the crab morphology were made with the aid of a camera lucida and compared to figures in the literature and museum collection material.

Abbreviations used: CW, carapace width; NHM, Natural History Museum, London; ovig., ovigerous; RMNH, Museum of Natural History, Leiden, The Netherlands; ZMA, the Zoological Museum, Amsterdam.

\section{SYSTEMATICS}

Order DECAPODA

Family OCYPODIDAE Ortmann, 1894

Genus Dotilla Stimpson, 1858
Dotilla intermedia De Man, 1888

(Figures 1-5)

Dotilla intermedia De Man, 1888: 135, pl. ix, figures 4-6; Kemp, 1919: 331, figures of \& 10; Gordon, 1941: 137, figure 11c; Vogel, 1984: 225, figures 2a \& 4.

Dotilla clepsydrodactylus Alcock, 1900: 367, pl. lxii, figure 2, 2a; Kemp, 1915: 226.

\section{MATERIAL EXAMINED}

Type material: Mergui Archipelago; $2 O^{7}$ syntypes (CW 3.5$3.9 \mathrm{~mm}$ ), 1 ㅇ syntype (CW $3.7 \mathrm{~mm}$ ) (ZMA 102540); Burma, Andaman Sea, Mergui Archipelago, Sullivan Island, 


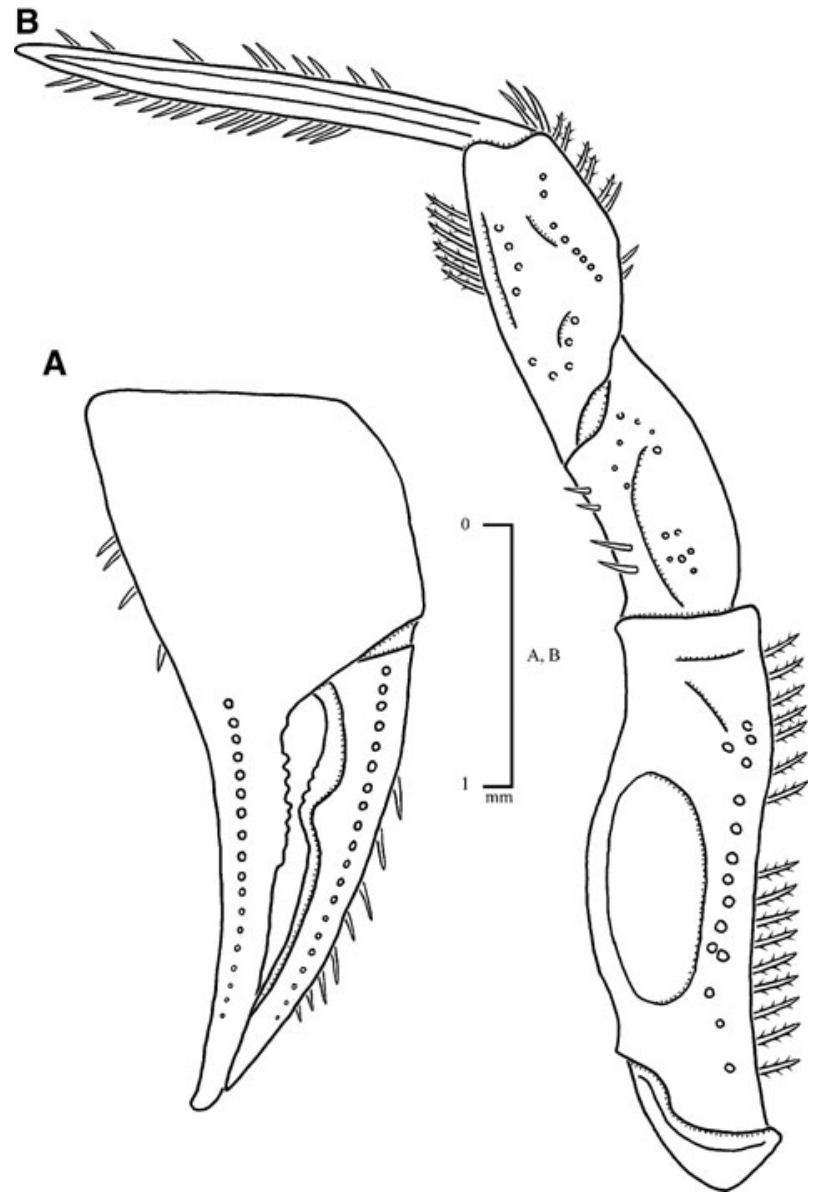

Fig. 3. Dotilla intermedia from the Laem Son National Park. (A) Right chela, anterior view; (B) fourth left ambulatory leg, dorsal view.

1880; $1 \mathrm{O}^{7}$ syntype (CW $\left.3.4 \mathrm{~mm}\right), 1$ 을 syntype (CW $\left.3.2 \mathrm{~mm}\right)$ (RMNH 27).

The large $\sigma^{7}$ specimen (CW $3.9 \mathrm{~mm}$ ) from Mergui Archipelago (ZMA 102540) is here designated as the lectotype and the remaining type specimens are considered paralectotypes.

Non-type material: Chaudipar, Balasore, Orissa, India; $6 \sigma^{7}$ (CW 5.4-6.4 mm) (NHM 1919.11.1.95-100); Mergui; $4 \sigma^{7}$ (CW 3.6-3.8 mm), 2 우 (CW 3.1-3.6 mm) (NHM 1886.52); Prapas beach and Bang Ben, Laem Son National Park, Thailand; $12 O^{\top}$ (CW 2.4-4.9 mm), 2 q ovig. (CW 3.6$3.7 \mathrm{~mm}), 10$ 으 (CW $2.4-4.4 \mathrm{~mm})$.

\section{DESCRIPTION}

Carapace (Figure 1A): broader than long, strongly sculptured with deep mid-dorsal groove running from front to posterior margin. Gastric region marked by five small lobules broadly forming five pointed star pattern. Single groove runs obliquely from side of mesogastric region to antero-lateral angle. Two grooves run obliquely from side of cardiac region to posterolateral angle. Posterior two-thirds of carapace bears distinct grooves that do not bifurcate anteriorly (unlike in $D$. fenestrata, D. malabarica, D. pertinax, D. sulcata and D. wichmanni), and run parallel to lateral margin (Figure $1 \mathrm{~B}$ ). Complete transverse groove present close to posterior margin. Two parallel grooves run from posterior groove to
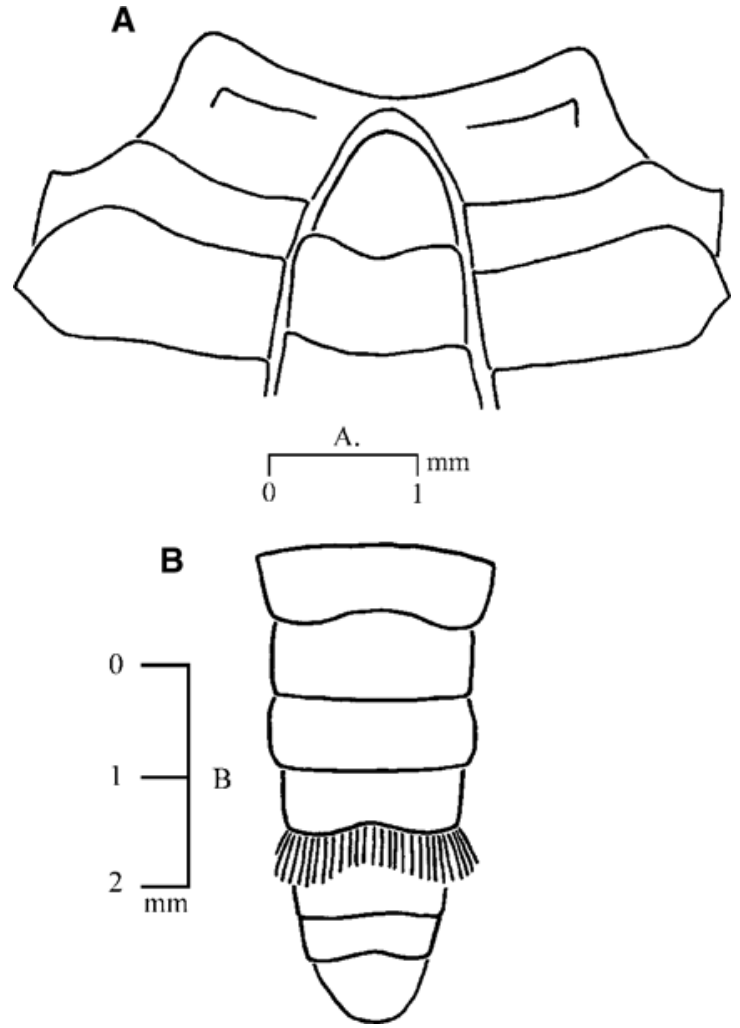

Fig. 4. Dotilla intermedia from the Laem Son National Park. (A) Male anterior sternal somites; (B) male abdomen.

edge of gastric region, marking lateral edge of cardio-intestinal region.

Second maxilliped (Figure 2): differentiated spoon-tipped setae found on different areas of second maxilliped. Spoon-tipped setae on carpus margin are bowl-shaped and plumose (Figure 2A). Spoon-tipped setae located on inner surface of merus not bowl-shaped, but resemble a three-tined fork that is curved at distal end. Peduncle of setae single stalked, with deep groove along axis (Figure $2 \mathrm{~B}$ ). On merus margin spoon-tipped setae are bowl-shaped with serrated edge to bowl (Figure $2 \mathrm{C}$ ).

Chela (Figure $3 \mathrm{~A}$ ): dactylus with a distinct tooth on middle. Propodus finger serrated on proximal half of cutting edge, granular ridge runs back from apex along propodus and onto palm for a short distance. Similar granular ridge runs along dactylus. Fingers at least 1.5 times length of propodus palm.

Fourth ambulatory leg (Figure $3 \mathrm{~B}$ ): dactylus approximately twice propodus length. Tympana present on both sides of merus. Tympanum on dorsal surface of merus occupies approximately third to half of total area of merus.

Sternum (Figure $4 \mathrm{~A}$ ): transverse ridge on first somite running either side of abdominal trough. Sternal tympana absent.

Abdomen (Figure $4 \mathrm{~B}$ ): comprises seven separate moveable somites. Distal margin of fourth somite, shallowly emarginate, overlaps fifth somite. There is a single band of setae on fourth somite, extending along the whole width of distal margin. Male and female abdomens are similar, not v-shaped and $\mathrm{u}$-shaped respectively.

First male pleopod (Figure 5): slightly sinuous appendage, approximately uniform in diameter throughout, slightly more slender towards tip. Tip of pleopod blunt with numerous 

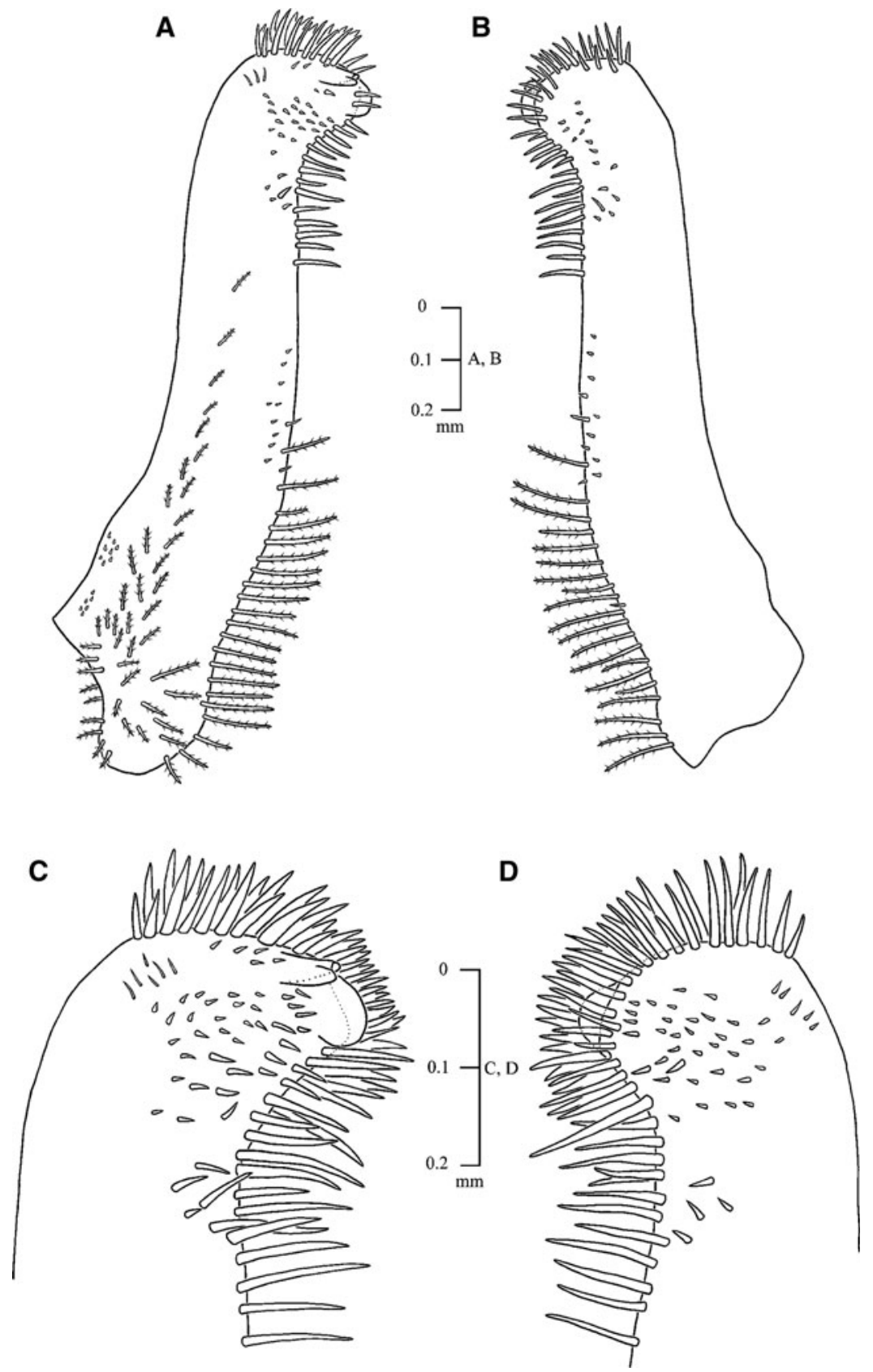

Fig. 5. Dotilla intermedia from the Laem Son National Park. (A \& C) right first pleopod, dorsal view; (B \& D) right first pleopod, ventral view.

unbranched setae. Proximal part has a fringe of plumose setae on outer edge. Dorsal surface has a line of plumose setae near to outer margin on proximal two-thirds of pleopod.

\section{HABITAT}

The crabs emerge at low tide to feed on the surface sediment around their burrows. Dotilla intermedia feeds using their chelipeds to scrape sediment into their mouthparts where a floatation mechanism separates organic material from the inorganic sediment, in a manner similar to Uca (Miller, 1961). The inorganic material is rejected from the base of the mouth as a feeding pellet, which is then pinched off by a chela and passed through the crab's legs. The crabs feed around the burrow in a radial pattern, laying down feeding pellets behind them (see Figure 6).
Dotilla intermedia are found within the intertidal zone between mean high water neap and mean low water neap on exposed moderate to fine sand beaches. On Prapas beach crabs were found at a mean density of $28 \mathrm{crabs} 0.25 \mathrm{~m}^{-2}$. At this mean density, the numbers of $D$. intermedia can reach approximately 4.1 million crabs along a $1 \mathrm{~km}$ stretch of beach (see Figure 7).

\section{REMARKS}

Kemp (1919) reported that males of Dotilla intermedia display two distinct dimorphic types, that he termed 'high' and 'low'. These morphs differ in the shape of the first male pleopod, the chela and in form of the first somite. The first pleopod of the 'high' male is short and robust, and furnished by numerous setae at the tip. The first pleopod of the 'low' male is more 


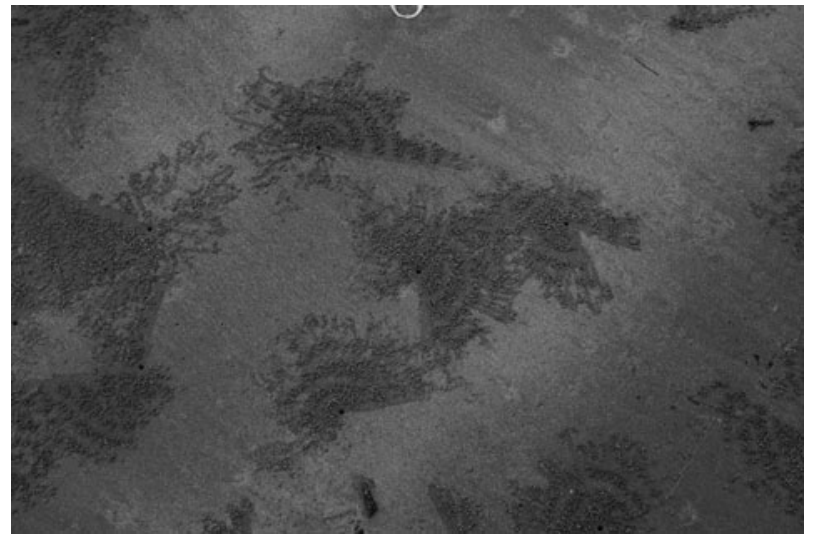

Fig. 6. Dotilla intermedia burrows at low tide on Prapas beach, Laem Son National Park, surrounded by feeding pellets.

slender, longer and more sinuous than the 'high' form, with the distal end bent at $90^{\circ}$ to the main stalk of the pleopod. The tip of the 'low' pleopod does not bear conspicuous setae. The 'high' male has a tooth on both fingers of the chela, and they form an hourglass shape when the chela is closed. The chela of the 'low' male only has a tooth on the moveable finger, which is positioned closer to the palm than in the 'high' male. The first sternal somite of the 'high' male bears a transverse ridge on either side of the abdominal trough, whilst the 'low' male has two triangular teeth that extend beyond the anterior limit of the abdominal trough (see Kemp, 1919: figure 10). The specimens collected from the Laem Son displayed a transverse ridge on the first sternal somite, along with a short and robust pleopod. Both of these features are typical of the 'high' male form. However, the Laem Son specimens only had a tooth on the dactylus, a character of the 'low' form. Kemp (1919) mentioned that the dimorphic characters of the first sternal somite and chela are not always well developed on small crabs. All specimens examined from the Laem Son were less than $5 \mathrm{~mm}$ in carapace width, suggesting that the 'high' male chela character may not have fully developed yet. In the male crabs larger than $5 \mathrm{~mm} \mathrm{CW}$ examined from India the 'high' male chela was always fully developed. Kemp (1919) stated that the shape of the first male pleopod

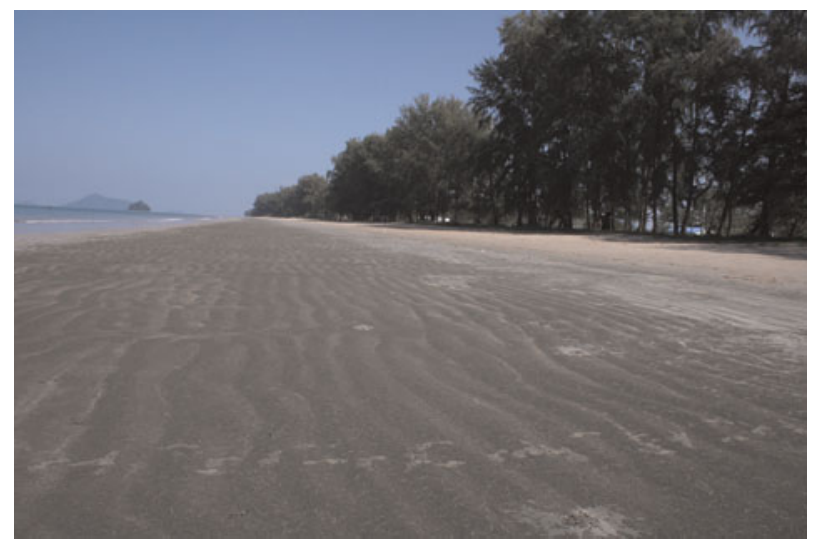

Fig. 7. Prapas beach, Ranong, Thailand, looking north showing burrow densities of Dotilla intermedia at low tide. This beach is $\sim 5 \mathrm{~km}$ long with an estimated 20.66 million crabs. remains constant between the two morphs, which provide support to the Laem Son specimens being the 'high' form of D. intermedia.

\section{DISTRIBUTION}

Dotilla intermedia appear to be restricted to the Bay of Bengal, ranging from near Madras in India, along the coast through to Maungmagan and the Mergui Islands in Burma, and southwards to Laem Son National Park, Thailand.

\section{DISCUSSIDN}

The identity of the specimens collected from Prapas beach and Bang Ben in the Laem Son National Park was determined as Dotilla intermedia by using the key in Kemp (1919). This identification was supported by reference to figures and descriptions of $D$. intermedia in the literature (De Man, 1888; Kemp, 1919; Gordon, 1941; Vogel 1984) and examination of type specimens. The carapace sculpture of the collected specimens closely agreed with the figures of D. intermedia in Kemp (1919). The shape of the first male pleopod agrees with figures of $D$. intermedia in Kemp (1919) and Gordon (1941), whilst the spoon-tipped setae of the second maxilliped are identical to those described for D. intermedia in Vogel (1984). Comparisons to museum collection material showed a strong resemblance, confirming the identification of the species from the Laem Son National Park to be $D$. intermedia.

The identification of these specimens represents the first time Dotilla intermedia has been reported from Thailand. Further investigations were made on beaches to the south of the Laem Son National Park to Phuket including Thae Muang Beach $\left(8^{\circ} 25^{\prime} 34^{\prime \prime} \mathrm{N} 98^{\circ} 14^{\prime} 14^{\prime \prime} \mathrm{E}\right)$, Mai Kao Beach $\left(8^{\circ} 09^{\prime} 59^{\prime \prime} \mathrm{N} 98^{\circ} 17^{\prime} 35^{\prime \prime} \mathrm{E}\right)$ and beaches by the Phuket Marine Biological Centre. None of the beaches examined were found to be inhabited by $D$. intermedia. However, no beaches were found with ecological characteristics similar to those found in the Laem Son, with differing sediment grain size and beach slopes. Those beaches having coarse sand were not occupied by any Dotilla crabs at all, although those with fine sand were inhabited by D. myctiroides (C.J. Allen and G.L.J. Paterson, personal observations). The grain size of beaches is hypothesized to limit which areas are available for settlement by $D$. intermedia (Allen et al., 2010). The Laem Son National Park may represent the south-eastern most limit of the range of $D$. intermedia around the Bay of Bengal. Further investigations along the western coast of Thailand are needed to confirm whether the Laem Son National Park does indeed mark the boundary of the distribution of $D$. intermedia.

\section{ACKNOWLEDGEMENTS}

This study was supported by a NERC CASE studentship (NER/S/A/2006/14217) to C.J.A. which is gratefully acknowledged. The authors would like to thank the staff of the Kasetsart University Ranong Coastal Resources Research Station, Kampuan, Thailand for their hospitality and for use of the facilities. Thanks are also due to members of the Tsunami Impact in Thailand Project for logistical support. We would also like to thank Charles Fransen (RMNH) and 
Dirk Platvoet (ZMA) for their hospitality and allowing examination of collection material at their institutions.

\section{REFERENCES}

Alcock A. (1900) Materials for a carcinological fauna of India. No. 6. The Brachyura Catometopa or Grapsoidea. Journal of the Asiatic Society of Bengal 69, 279-456.

Allen C.J., Paterson G.L.J., Hawkins L.E., Hauton C., Clark P.F. and Aryuthaka C. (2010) Zonation on tropical sandy beaches: a case study using Dotilla intermedia. Marine Ecology Progress Series 408, 97-107.

Gordon I. (1941) Notes on some Indo-Pacific crabs (Crustacea, Decapoda). Proceedings of the Linnaean Society, London 153, 123-140.

Kemp S.K. (1915) Fauna of Chilka Lake. Memoirs of the Indian Museum $5,199-325$.

Kemp S.K. (1919) Notes on the Crustacea Decapoda in the Indian Museum. XII. Scopimerinae. Records of the Indian Museum 16, $305-348$.

De Man J.G. (1888) Report on the podophthalmous Crustacea of the Mergui Archipelago, collected for the trustees of the Indian Museum, Calcutta, by Dr John Anderson, FRS, Superintendant of the Museum. Journal of the Linnaean Society, London (Zoology) 22, $1-312$.

De Man J.G. (1892). Decapoden des Indischen Archipels. In Weber D.M. (ed.) Zoologische Ergebnisse einer reise in Niederländisch Ost-Indien. Brill: Leiden, pp. $265-527$, plates $15-30$.

Miller D.C. (1961) The feeding mechanisms of fiddler crabs, with ecological considerations of feeding adaptations. Zoologica 46, 89-100.
Milne-Edwards H. (1852) Observations sur les affinités zoologiques et la classification naturelle des Crustacés. Annales des Sciences Naturelles 18, 109-166, plates 3 \& 4. [Mélanges Carcinologiques, 73-128].

Ortmann A.E. (1894) Die Decapoden-Krebse des Strassburger Museums mit besonderer Berücksichtigung der von Herrn Dr. Döderlein bei Japan und bei den Liu-Kiu-Inseln gesammelten und zur Zeit im Strassburger Museum aufbewahrten Formen. Theil VIII. Abtheilung: Brachyura (Brachyura genuina Boas), III. Unterabtheilung: Cancroidea. 2. Section: Cancrinea, 2. Gruppe: Catametopa. Zoologische Jahrbücher, Abtheilung für Systematik, Geographie und Biologie der Thiere 7, $683-772$

Stimpson W. (1858) Prodromus descriptionis animalium evertebratorum, quae in Expeditione ad Oceanum Pacificum Septentrionalem, a Republica Federata missa, Cadwaladaro Ringgold et Johanne Rodgers Ducibus, observavit et descripsit. W. Stimpson. Proceedings of the Academy of Natural Sciences, Philadelphia 10, 31-40.

Vogel F. (1983) A redescription of Dotilla malabarica Nobili, 1983 (Decapoda, Brachyura, Ocypodidae). Crustaceana 46, 157-163.

and

Vogel F. (1984) Comparative and functional morphology of the spoontipped setae on the second maxillipeds in Dotilla Stimpson, 1858 (Decapoda, Brachyura, Ocypodidae). Crustaceana 47, 225-234.

\section{Correspondence should be addressed to:}

C.J. Allen

School of Ocean and Earth Science

University of Southampton, National Oceanography Centre, Southampton

European Way, Southampton, Hants SO14 3ZN, UK

email: chris.allen@noc.ac.uk 